\title{
Kenneth J. Gergen and Social Constructionism
}

\author{
Girishwar Misra $\cdot$ Anand Prakash
}

Published online: 14 April 2012

(C) National Academy of Psychology (NAOP) India 2012

Aaano bhadrah kratavo yantu vishvatah.

Let noble thoughts come from all directions. -A Vedic saying

The intellect acquires critical acumen by familiarity with different traditions. How much does one really understand by merely following one's own reasoning only? -Bhartrhari (Vākyapadīya 2.484)

Constructionism opens the door to multiple ways of seeing the world; it is an invitation to creativity, and it asks the researcher to think carefully about what is being contributed to the culture and the world.

-Kenneth J. Gergen (Interview in this issue)

This special issue of Psychological Studies (PS) is in honour of Kenneth J. Gergen's seminal work on social construction. During the last four decades he has been leading debates through which he has reoriented the theory and practice of psychology. Indeed Ken has inspired a large body of research and application which has crossed disciplinary and national boundaries. This issue of PS offers a state-of-the art collection of articles reflecting on Ken's work and the growth of social constructionism in different domains. The idea to bring out this special issue germinated in December 2009 when Ken and his wife Mary visited Delhi University and shared constructionist ideas with a cross section of the community of present and future Indian psychologists. The day he lectured here, we also

\section{G. Misra $(\varangle) \cdot$ A. Prakash}

Department of Psychology, Arts Faculty Extension Building,

University of Delhi,

Delhi 110007, India

e-mail: misragirishwar@gmail.com

A. Prakash

e-mail: anandp0001@yahoo.com celebrated his 75 th birthday. We also decided then to organize this issue of the journal to present an account of the multifaceted growth of social constructionism over the years. We invited a range of scholars who have ventured to use social constructionism to give first hand accounts. Our request was enthusiastically responded to and the result is this issue of Psychological Studies. The issue begins with an interview of Ken and concludes with Mary's personal reflections about the making of Ken. Other contributions reflect and relate to Ken and constructionism. We hope the contributions to this issue will invite the readers to engage dialogically with social constructionism and the challenges faced in our contemporary world.

As a social psychologist trained at the Universities of Yale and Duke, Ken completed his doctoral work with Edward E. Jones in 1962 and started his professional life at Harvard as Assistant Professor in the Department of Social Relations. In 1967 he came to Swarthmore College in Philadelphia where he is currently a Senior Research Professor. He has been on visiting assignments to the Universities of Heidelberg, Sorbonne, Rome, and Kyoto. He has widely travelled in different parts of the world and has collaborated with scholars from psychology and many allied fields of human inquiry. In 1993, he and his colleagues launched the Taos Institute as a nonprofit organization dedicated to bringing constructionist ideas together with societal practices. The Institute now offers conferences, workshops, a Ph.D. program, certificates, publications, and on-line resources. Ken is serving as its President. He is also an adjunct professor at Tilburg University.

As a warm, considerate, and engaging person, Ken is very generous with his ideas. In his academic journey he has been coherent with his social construction theory and maintained his course while at the same time continually revising, expanding and evolving his contributions. During his long career, Ken has tirelessly concentrated on reflection 
and action using interpretation and construction as key tools. He has now become an institution in himself.

Going beyond the insular orientation of psychology, Ken has often been crossing the disciplinary boundaries to create bridges and searching for shared spaces to foster dialogue. Building on developments in contemporary discourses in the philosophy of science, cultural studies, and interpretive inquiry, Ken has widened the net of psychological exploration and situated it in a culturally informed dynamic intellectual space. He has critically addressed many concepts and assumptions that are taken for granted by those who are educated in the positivist mould of knowledge creation, which has been informing the mainstream psychological investigations.

The constructionist turn has been controversial. It has met with resistance and contested by those who, like physical scientists, subscribe to an essentialist view of reality and claim legitimacy for the scientifically produced and represented 'objective' knowledge. Positioned in such a scenario, Ken has indefatigably tried to demystify the conceptual, theoretical, and methodological implications of such knowledge claims by critiquing and offering empowering reconstructions (see Gergen 1982, 1985, 1994, 2001, 2009). In so doing, he has demonstrated an unparalleled intellectual courage and patient striving. Ken's early work has been dominated by a critical stance but in later works he has moved toward developing an alternative vision for social life characterized by joint action, performance, relational nature of constructed realities, and cultural inclusiveness.

A moment's reflection on the contemporary social reality would bring home the point that the perspective of constructionism has become more pertinent today than ever before, especially on the following two counts. First, it respects the plurality and diversity in our social world. Instead of a singular or hegemonic view of reality, constructionism entertains multiple realities which emerge and therefore offers innovative ways of appreciating and shaping reality (Gergen et al. 1996). Recognizing 'others' on their terms builds trust and encourages dialogue. The move from the notion of objective reality to reality as construction opens the scope of interchange, collaboration, and sharing. Explicating and elaborating the significance and implications of these ideas for a better world has been a major theme in Ken's work. Using this as a building block, Ken has ventured to envision collaborative practices in the domains such as health, organization, human development, and education.

Second, social constructionism reconfigures human discourses in a non-foundationist and non reductionist ways. In his groundbreaking paper titled Social Psychology as History published in 1973, Ken drew attention to the historically situated nature of social psychological inquiry and the resulting theory and knowledge. He observed:

'Perhaps the primary guarantee that social psychology will never disappear via reduction to physiology is that physiology cannot account for the variations in the human behavior over time... To be sure, varying responses to the environment rely on variations in physiological function. However, physiology can never specify the nature of the stimulus inputs or the response context to which the individual is exposed. It can never account for the continuously shifting patterns of what is considered the good or desirable in society, and thus a range of primary motivational sources for the individual. However, while social psychology is thus insulated from physiological reductionism, its theories are not insulated from historical change'. (1973, Pp. 315-316).

It may be noted that in recent years there is revival of interest among psychologists in accounting everything in terms of neuro-physiological processes and mechanisms. Proposals of brain-based understanding have been on increase. There is strong assertion that almost all psychological processes can be ultimately traced to brain processes. This is in tune with the idea of psychology as natural science. As such it required grounding of mental processes in neuro-physiology. In 2010 Ken addressed the problems involved in such reifications. In a paper titled The Acculturated Brain Ken has raised some important issues for the discipline as well as society. Examining the socio-cultural implications of brain based explanations he observed that brain determinism implies a kind of neo-fatalism and makes important concepts empty of values. In contrast, Ken noted that the brain may be thought

'as an instrument for achieving culturally constructed ends. All attempts to infer mental states from behavioral observation are suspended, then, on a network of conjectural assumptions...Brain scan data do not solve the problem of inference, but simply remove it from one site of speculation to another. Brain scans do not speak for themselves. To read them as evidence of depression, deceit, trust, empathy, political preferences, and so on, is essentially to participate in a tradition of cultural interpretation. In this sense, making connections between mind and brain is a form of cultural projection. That is, one must participate in a cultural tradition in which the existence of mental states is presumed in order to read brain scans in their terms' (Gergen, 2010, p. 7).

To Ken 'brain may be a major facilitator of our actions, it is not their progenitor' (Gergen, 2010, p.16). This view acknowledges the value of indigenous psychologies rooted in diverse cultures. The Western psychology's cultural imperialism keeps other constructions on the margin. He asks: 'Why there has not been a lively interest in exploring the neural basis of karma, swabhava, swadharma, and sthita pragya, all significant to human functioning in Hindu psychology'? 
(Gergen 2010, P. 8). In seeing human activities as culturally bound, we can envision alternative futures, especially with the understanding of phenomenon like neural plasticity.

A concerted investment in relational processes has become a key concern of Ken's work. He notes that in today's era of rapidly changing 'glocal' boundaries, the idea of an individual appears dislocated and inept. He also observes that the celebration of the individual mind as a locus of capacity for autonomous thought and judgment is a legacy of Western Enlightenment. Treating the individual mind as the primary reality creates a gulf between the self and other. In this scheme we don't know the other mind so one need not trust the other. As a consequence, relationships are becoming artificial and of secondary importance and we are moving toward a culture of loneliness, self-centeredness, and antagonism, with reduced degree of community participation.

The process of knowledge generation is primarily relational in nature. As Ken has nicely put, "reasoning well" is not to step outside of relationships for a "private moment", but to participate fully within them. He firmly believes that communally shared understanding and values are constitutive of science. Also, knowledge deeply involves the work of interpretation. Thus knowledge may not be more or less true but its functionality in terms of culturally accepted beliefs and values may be low or high. Thus knowledge originates from communities and not from the individual minds. In this way social construction becomes a framework within which the production and use of knowledge is embedded.

\section{Contributions to The Present Issue of PS}

This special issue of Psychological Studies begins with a recent interview of Ken by Liping Yang, a scholar from Nanjing Normal University, China. Ken has provided a candid account of his current engagements and responded to a range of questions related to theory and application of constructionism. He declares that it is the dialogue which is the ultimate aim of his endeavours. To him, social constructionism works as a meta-theory of knowledge and also furnishes a theory that accounts for the happenings in life. To him knowledge is a communal construction. He says:

When we talk about the world, it is not a mirror of the world. It is a way of using words for some purpose, one interpretation among a possible infinity. So there is no truly true account, no truth with the capital " $\mathrm{T}$ ", no objectivity that is opposed to a subjective account.

Ken's interview is followed by a thought provoking contribution by Shotter. Reflecting on Relational Being (Gergen 2009), he notes that the basic way of being in the world is to be constantly in motion. We live continuously in the midst of change. However the linguistic habit leads us into thinking that what is new for us must, simply, be made from what is already in existence. Shotter notes that the notion of relational embedding in our surroundings is entirely new in Ken's recent work. The capacities for collaborative inquiry help to better the conditions of our own lives and our living of them together. Our ontology lies 'within a process of relational flow, in which there is both, continuous movement toward constraint, and an openness to the evolution of meaning' (Gergen, 2009, p.46). Human actions have no meaning in and of themselves; only within an ongoing confluence of joint- or co-action can they begin to have a practical meaning. Shotter posits that if our living activity is truly determined by that which has not yet been achieved, but which is in fact anticipated (as at least possible) in the flow of already occurring events, then we must contemplate the possibility of a world that is still coming into being - a world within which the many different flowing strands of different activity intertwine, become entangled with each other, and then sometimes separate; a turbulent, not-yetsettled, dialogically-structured world - a world that is still in the making. As a result, the whole field of psychological inquiry must take on a new cast - especially if it is to take on the relational responsibility for the practical creation of worlds which sustain, rather than merely exploit, the relational flow within which the confluences responsible for their emergence occur. We must conduct our inquiries from within the midst of turbulent, flowing processes.'

In the next contribution Anderson shares her reflections on how Gergen has offered and substantiated a shift from the individual to the social, including the shift of the focus on knowledge from an individual cognitive construction to a communal one, from language as representational to language as a dynamic social process, and from the notion of a person as a bounded self to the notion of a person as a 'multi-being'. Against this backdrop she discusses therapy as relational recovery. She argues that the constructionist view challenges the hierarchy and dualism in therapeutic systems. The emphasis is on using the dynamic process of dialogue with each other, others and one's self. Thus the relational and dialogic conversational endeavour becomes central. Dialogue invites and requires of its participants a sense of mutuality. These characteristics distinguish dialogue as a collaborative and generative joint activity.

Situating constructionism in the context of communication discipline, McNamee observes that Ken's work inspires and influences practitioners working in many areas. It offers resources such as centering relational processes which, in turn, generate the expansion of collaborative, participatory practices that embrace alternative worldviews through a reflexive stance. Ken has challenged himself and others to stay on the edge because it is on the edge that new relational possibilities can be created. Ken's position is that "the limits of my relations are the limits of my resources". This implies 
the salience of situated joint action. It is argued that meaning is constructed with others and realized in the collaborative performances of people in relation.

In the next paper Yu and Sun have focused on organizational processes. They note the limitations of reductionist approach which essentializes the 'social' through the usage of language, which itself is a product of culture. The social constructionist work has brought into focus the fact that social psychological theories tend to reflect historical and cultural circumstances, rather than capturing laws of nature. The implications of this view for understanding organizational processes are elaborated.

In the next contribution Wortham and Jackson examine the significance of relational approach for educational research and practice. They argue that education should involve a set of processes to enhance relationships rather than enhancing the individual's mind and offer critique of the prevailing assumptions. They elaborate the emerging emphasis on individuals as woven into contexts and knowledge as produced in relationships and bring out the implications of knowledge as 'contextualized'.

Population dynamics are changing and the challenge of graceful aging is widely recognized as one of the key societal issues across the globe. In this context Randall has addressed the problem of aging which simultaneously occurs in physical as well as psychological domains. More specifically the idea of biographical aging is distinguished from biological aging. Randall argues that an "inside" perspective views aging in more positive terms, and aging people can be conceptualized as persons with (and within) complex webs of stories. Aging may be configured as a (potentially) creative process, a process of not merely getting old, but consciously growing old. The conceptual analysis presented by Randall brings a new orientation to aging.

In the next contribution, Panda has examined the multilingual education (MLE) discourse and practices in the Indian context. The choice of MLE model is influenced by the dominant construction of the problem of tribal children's learning in regular government schools as one of 'poor' or 'inadequate' bridging between their everyday language and concepts and the school language and the academic concepts. 'Bridging' and 'exit', therefore, became two foundational metaphors of the Indian MLE programmes. The paper deconstructs these metaphors and argues for a critique in pedagogy.

Using an autoethnographic lens, Sharma notes that the communal construction of mental illness makes recovery a daunting challenge since society largely perceives the psychiatrically ill as 'deficient'. Not only does one have to deal with the illness itself, but has to address the perpetual stigma associated with the labelling. Using a personal narrative, it is shown how one constructs structures which help to make oneself stable and empowered from within.

The domain of helping professions is the theme of the next contribution in which Romaioli explores the potential contribution of the social constructionist paradigm to harmonize different perspectives on therapy. In particular, attention is drawn to three premises: (1) the individual psychic world is constructed within relational processes, mainly through dialogue (2) in general, discourses can be classified as either generative or degenerative, and (3) individuals construct their life narrative according to a common-sense that - more or less openly_draws its concepts from "official" psychology theories. This relational perspective allows one to appreciate the implications for clinical practice, where therapist and client are seen as "multi-beings" and therefore endowed with multiple views.

Using a dialogical style Paré and Sutherland have addressed the challenges in practice and examine concerns in counselling education following a social constructionist perspective. Building on the centrality of relationship as the key theme they have written the article in two voices. Paré's reflections occupy the major portion of the contribution; however, his account often takes turns by the reflective interventions by a second counsellor educator, Sutherland. They draw attention to the relational aspect of knowledge and meaning and reflexive cooperation. They argue that descriptions and explanations are accomplishments of coordinated human action, and relationships provide various forms of choices for going forward, and are also impacted significantly by the choices made.

Taking to a different plane of deliberation Kwee, a Buddhist scholar and practitioner, argues that the psychology of relational Buddhism is a cutting-edge practical understanding of life. He notes that while living in an ocean of relationships from the cradle to the grave, it is significant to recognize the interpersonal significance of the binding "we". In the context of the theory of dependent origination, to act is to inter-act and to be is to inter-be. This deep insight goes well with the assumptions of social constructionism. Relational Buddhism invites the co-creation of inter-being-in-between-selves and of a "non-foundational morality of coordinated action" to render "team spirit for humanity" with congenial bonds as a lifeline.

Priya has addressed the problem of suffering and healing and offers a critique of the Western biomedicine that focuses on diagnosis and treatment of the symptoms of a disease. Using a social constructionist paradigm as a meta theory, the human experiences of suffering and healing are explicated and connected with the works of Eric J. Cassell and Arthur Kleinman. It is argued that suffering and healing experiences are socio-historically contextualized. In this framework the dialogic partnership between the researcher and the participant becomes a meaningful medium to understand such experiences.

In the next paper entitled "On a Train from Morgantown" Jones has shared a film script. It is built around the fictive historical dialogue between a German developmental psychologist, Klaus Riegel and Kenneth Gergen, an American 
social psychologist. Both have just presented papers at a conference and are boarding a train to return to their respective places. The author meets them as they are travelling from Morgantown. Their conversation ignites ideas that would propel Gergen into abandoning metatheories and lighting the spark that began the concept of social constructionism. The conversation represents the interface between old ideas of grand theories and the birth of new ideas inspired by the possibilities of a smaller, more intimate world view. Jones uses retrospective imagining supported by narrative biographical theory. He extends these to the illusory biographies of others constructed within a sense of other as created by an imaginative projection of self onto their worlds.

In the final contribution, Mary Gergen, a feminist scholar and life partner of Ken, reconstructs Ken's journey over the years by relating to places and people in a historical context. Her narrative offers a deeply reflective account of the person that Ken is, his zeal for writing, sharing and relating through dialogue. Amidst diverse moves, turns, challenges, and collaborations Ken has been continuously engaged in appreciating the complexities of human life as it unfolds. Mary offers insights into the evolution of Ken's passions, habits and motivation for his wide-ranging concerns for humanity - his being and his ways of becoming - through engagements in dialogical reflection and action.

Ken's creativity, imagination and engagement continue and his ideas have made their presence felt around the world. The constructionist view is increasingly being used by a range of researchers and practitioners. It is assuming the form of a paradigm. However, it makes no claims for one truth. It opens the door to multiple ways of engaging in knowledge. The consciousness of multiplicity is indeed an emerging global sensitivity. In this context various relational processes like dialogues, collaborations, networks and negotiations are critical. The social constructionist move from monologue to dialogue, from isolated to relational rationality, is the future.
Together these contributions map out a clear and compelling vision of a constructionist perspective from an insider's perspective. They seek to explain the dialogical nature of the social world. This issue PS is our attempt to contribute to the efforts in this direction and to recognize the accomplishments of a brilliant academic leader. We present this issue with the hope that it will ignite a spirit of productive and useful deliberation for making human lives more fulfilling through an open minded dialogue and reflexivity.

Acknowledgments We thank Ken, Mary and the authors who contributed papers to this issue. We also thank Nivida Chandra, Purnima Singh, Rekha Singhal, Preeti Kapur and the Indian Council of Social Science Research who helped in organizing the visit of Ken to Delhi University. The preparation of this special issue was facilitated by the USEFI's Fulbright-Nehru Visiting Fellowship to one of the editors (GM) and support available at Department of Psychology, New School of Social Research, New York.

\section{References}

Gergen, K. J. (1973). Social psychology as history. Journal of Personality and Social Psychology, 26, 309-320.

Gergen, K. J. (1982). Toward transformation in social knowledge. New York: Springer-Verlag, (2 ${ }^{\text {nd }}$ Edition, London: Sage, 1994)

Gergen, K. J. (1985). The social constructionist movement in modern psychology. American Psychologist, 40, 266-275.

Gergen, K. J. (1994). Realities and relationships. Cambridge Mass: Harvard University Press.

Gergen, K. J. (2001). Social construction in context. London: Sage.

Gergen, K. J. (2009). The relational being: Beyond self and community. New York: Oxford University Press.

Gergen, K. J. (2010). The acculturated brain. Theory and Psychology, $20,1-20$.

Gergen, K. J., Gulerce, A., Lock, A., \& Misra, G. (1996). Psychological science in cultural context. American Psychologist, 51, 496-503. 